\title{
Temporal change in foraging behaviour of the fish Coryphaenoides (Nematonurus) yaquinae in the central North Pacific
}

\author{
John D. Armstrong ${ }^{1,}$, Imants G. Priede ${ }^{1}$, Kenneth L. Smith $\mathrm{Jr}^{2}$ \\ ${ }^{1}$ Department of Zoology, University of Aberdeen, Tillydrone Avenue, Aberdeen AB9 2TN, Scotland, UK \\ ${ }^{2}$ Marine Biology Research Division, Scripps Institution of Oceanography, University of California, San Diego, La Jolla, California 92093, USA
}

\begin{abstract}
Deep-sea grenadier fish Coryphaenoides (Nematonurus) yaquinae were attracted to a baited free-fall video camera and tracking vehicle during 10 deployments in the central North Pacific $\left(31^{\circ} \mathrm{N}, 159^{\circ} \mathrm{W}\right)$ at a depth of $5800 \mathrm{~m}$. The mean time of arrival of the first fish was $31.0 \mathrm{~min}$ after landing on the sea floor. The mean number of fish within camera view increased to a peak of 5.25 at $90 \mathrm{~min}$ after landing and decreased thereafter The initial arrival rate was 0.06 fish $\mathrm{min}^{-1}$, and mean fish staying time was $122 \mathrm{~min}$. The staying time was much shorter than in previous work at this site, suggesting a change in food supply with time of year Grenadiers were tracked using ingestible acoustic transmitters. The mean time until transmitter ingestion after the bait landed was $85.1 \mathrm{~min}$. Fish that swallowed transmitters dispersed at radial rates of 1 to $20 \mathrm{~cm} \mathrm{~s}^{-1}$, and all had departed to a range of $>1000 \mathrm{~m}$ by $13 \mathrm{~h}$ after landing. Movements to an altitude of $>15 \mathrm{~m}$ were recorded for $60 \%$ of fish tracked and occupied $12.9 \%$ of total tracking time. Bottom current speeds were between $<1$ and $9 \mathrm{~cm} \mathrm{~s}^{-1}$ with a tidal rhythmicity.
\end{abstract}

Deep-sea macrourid fish, Coryphaenoides (Nematonurus) armatus and $C$. (N.) yaquinae, are attracted to baits deployed at abyssal depths (Wilson \& Smith 1984). Movements of these fish can then be tracked since they will swallow (Priede \& Smith 1986) and retain (Armstrong \& Baldwin 1990) acoustic transmitters. Earlier work has compared arrival rates and staying time of grenadiers at a standard bait in contrasting areas of the Pacific Ocean (Priede et al. 1990). The areas studied were a relatively eutrophic region at $4400 \mathrm{~m}$ under the California current (Stn F, 32 $50^{\prime} \mathrm{N}$, $124^{\circ} \mathrm{W}$ ) and an oligatrophic station at $5800 \mathrm{~m}$ under the central North Pacific gyre (CNP, $\left.31^{\circ} \mathrm{N}, 159^{\circ} \mathrm{W}\right)$. Priede et al. (1990) were able to record the range and the degree of vertical movement of acoustically tagged fish at Stn $\mathrm{F}$ but not at CNP.

\footnotetext{
- Present address: SOAFD, Freshwater Fisheries Laboratory, Pitlochry, Perthshire PH16 5LB, UK
}

The present study collected acoustic tracking data from CNP to supplement the previous work. The study was conducted at a different time of the year to earlier work at CNP and therefore allows an assessment of temporal variation in foraging behaviour of Coryphaenoides yaquinae, the only grenadier species recorded from this area (Wilson \& Waples 1983).

Methods. First fish arrival times and the change in fish numbers around a standard mackerel bait were recorded using the free-fall vehicle (FVV) described by Priede et al. (1990). Photographic data were collected during 10 deployments of the FVV between 30 March and 23 April 1989. Either 2 or 3 baited acoustic transmitters were included on each of 8 of these deployments; range and altitude of fish that swallowed these transmitters were also recorded on the FVV. The acoustic recording system utilised in this study had a maximum range of over $1000 \mathrm{~m}$, substantially greater than that in the earlier study. Current speed was measured on a separate mooring using a current meter (SIO Model 6 with Savonius rotor and directional vane) suspended at 2 to $3 \mathrm{~m}$ above the seabed.

Results. The delay between FVV landing and arrival of the first fish seen swimming against the current ranged from 9 to 54 min with a mean of $31.0 \mathrm{~min}$ ( $\mathrm{n}=$ $10, \mathrm{SD}=11.28$ ). On 2 occasions fish that apparently did not detect the food were seen swimming across and down-current; these were excluded from the analysis since they were apparently not responding to the odour plume from the bait (Wilson \& Smith 1984).

Mean maximum numbers of fish within camera view increased steadily to a peak of 5 fish at ca 90 min after landing (Fig. 1). Thereafter the numbers gradually declined to a mean of less than 1 fish at $12 \mathrm{~h}$ from landing. The equation of Priede et al. (1990) was fitted to the data to give estimates of the initial arrival rate of fish $\left(\alpha_{0}, \min ^{-1}\right)$, mean fish staying time $(\beta$, min $)$ and a 


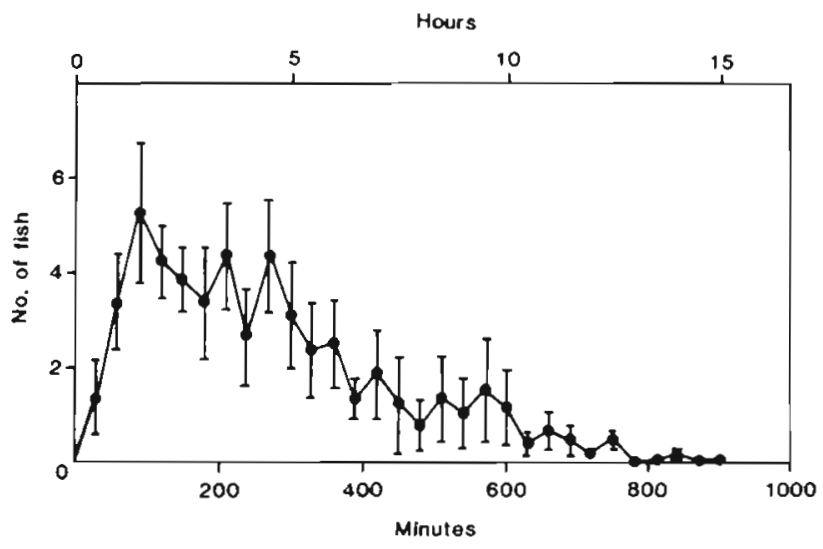

Fig. 1. Coryphaenoides (Nematonurus) yaquinae. Video observations of mean ( $\pm \mathrm{SE}$ ) number of grenadier fish within camera view, an area of ca $2 \mathrm{~m}^{2}$ of seafloor, in relation to time after landing from 10 deployments at Stn CNP. Means are given for the maximum number of fish observed in each $1 / 2$ or $1 \mathrm{~h}$ period, depending on sampling frequency

bait decay constant $(x)$. The best fit of this model was found by a chi-squared comparison of observed and predicted values in a reiterative algorithm. This generated values of $\alpha_{0}=0.06 \mathrm{~min}^{-1}, \beta=122 \mathrm{~min}$ and $\mathrm{x}=$ 0.004 .

Mean time until transmitter ingestion (after landing) was $85.1 \mathrm{~min}(\mathrm{n}=10, \mathrm{SD}=64.11)$. Ingestion was not always visible due to limitations of video resolution or obstruction of view by fish; however, there was no evidence of any removal of transmitters by animals other than grenadiers.

Of the transmitters deployed, 10 reached the seafloor correctly tuned and could be tracked. All of the fish that swallowed transmitters had disappeared out of range within $16 \mathrm{~h}$ of landing, with overall departure speeds of from 1 to $20 \mathrm{~cm} \mathrm{~s}^{-1}$ (Fig. 2). Excursions to altitudes exceeding $15 \mathrm{~m}$ above the seafloor were recorded for $60 \%$ of the fish and were recorded in $12.9 \%$ of all observations. Current speeds at CNP ranged from $<1$ to $9 \mathrm{~cm} \mathrm{~s}^{-1}$ and were characterised by a distinct semidiurnal rhythmicity.

Discussion. Grenadier behaviour recorded in this study is compared with that from Priede et al. (1990) for CNP in the summer/autumn season and for a shallower and more eutrophic area (Stn F) in Table 1. The range of radial dispersal velocities of grenadiers in the present study is very similar to that for fish at Stn F. It is notable that current velocities at the 2 stations are also similar. The range of the tracking system employed in the present study is double that previously possible in the deep sea. The results show that the active movements previously observed continue as fish move further away from the bait source.

Vertical movements by macrourids occurred at CNP

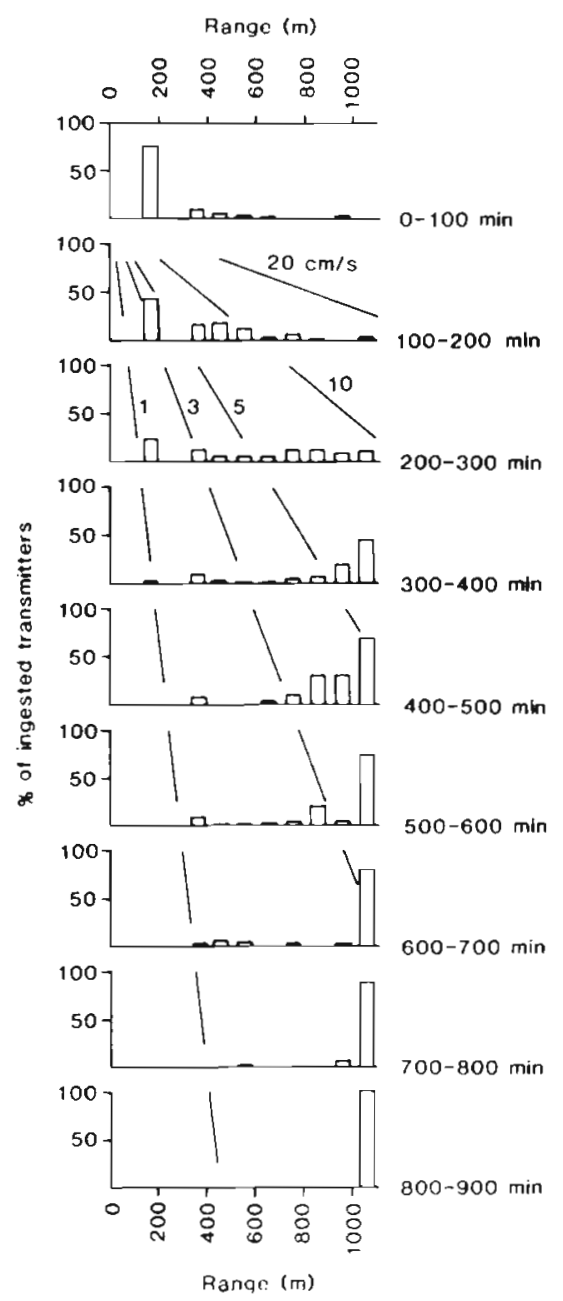

Fig. 2. Coryphaenoides (Nematonurus) yaquinae. (a) Dispersal pattern of 10 grenadier fish that ingested long-range transmitters. Range $(m)$ is the radial range from the vehicle. The frequency distribution of ranges of transmitters that have been ingested is shown for different times after vehicle touchdown; at 0 to $100 \mathrm{~min}$, not all the transmitters have been ingested and most of these are still within $330 \mathrm{~m}$ of the food source; at 800 to $900 \mathrm{~min}$, all transmitters are over $1000 \mathrm{~m}$ away from the food source. The radial lines indicate the rate of progression expected at different radial velocities, in $\mathrm{cm} \mathrm{s}^{-1}$ For ranges within $330 \mathrm{~m}$, the detection system was saturated; consequently the first histogram bar covers a range of 0 to $330 \mathrm{~m}$. and fish numbers are then grouped in $100 \mathrm{~m}$ blocks

(12.9\% of the time) but not at Stn $F(0.0 \%$ of the time) (Table 1), suggesting that individuals lead a more pelagic existence at the more oligotrophic station. This trend is similar to variations in vertical distribution of the scavenging amphipod Eurythenes gryllus at Stns F and CNP (Smith \& Baldwin 1984a, Baldwin \& Smith 1987). For amphipods, it has been argued that occupation of a position away from the sea floor enhances the chances of detecting chemical plumes dispersing from carrion (Ingram \& Hessler 1983, Smith \& Baldwin 
Table 1. Coryphaenoides (Nematonurus) yaquinae. Comparison of fish arrival and dispersal data at $\mathrm{Stn} C \mathrm{CNP}\left(31^{\circ} \mathrm{N}, 159^{\circ} \mathrm{W}\right)$ during early spring (present study) and at CNP during summer/autumn and Stn F ( $32^{\circ} 50^{\prime} \mathrm{N}, 124^{\circ} \mathrm{W}$ ) (data from Priede et al. 1990 )

\begin{tabular}{|c|c|c|c|}
\hline \multirow[t]{2}{*}{ Variable } & \multirow[t]{2}{*}{ Stn $F$} & \multicolumn{2}{|r|}{ Stn CNP } \\
\hline & & Summer/autumn & Spring \\
\hline$\alpha_{0}\left(\right.$ fish $\left.\min ^{-1}\right)$ & 0.11 & 0.05 & 0.06 \\
\hline$\beta(\min )$ & 60 & 400 & 122 \\
\hline$x$ & 0.012 & 0.003 & 0.004 \\
\hline First fish (min) & 15.7 & 43.5 & 31.0 \\
\hline Pop. size $\left(\mathrm{km}^{-2}\right)^{\mathrm{a}}$ & $601^{b}$ & $78^{\mathrm{b}}$ & 154 \\
\hline Ingest. time (min) & 53.6 & $250.0(\mathrm{n}=2)$ & $85.1(n=10)$ \\
\hline Dispersal rate $\left(\mathrm{cm} \mathrm{s}^{-1}\right)$ & $1-10$ & & $1-20$ \\
\hline Altitude ( $\%$ time $>15 \mathrm{~m}$ above bottom) & $0 \%$ & & $12.9 \%$ of total time; $60 \%$ of fish \\
\hline
\end{tabular}

1984a). A similar interpretation can be applied to the vertical distribution of grenadiers, with the consequent implication that fish at CNP forage more actively on food falls than those at Stn F. It is also possible, however, that predator-prey interactions between grenadiers and amphipods influence their distributions.

Fish arrival time is always lower at Stn F than at CNP, suggesting a lower grenadier density in the central North Pacific (Table 1). Estimates of grenadier population density calculated with the equation of Priede et al. (1990) indicate that there is a 4 - to 10 -fold difference between Stn F and CNP [note that the values in Priede et al. (1990) are erroneously given as 10 times the true value]. Population density of grenadiers estimated using this method correlates closely with trawl sampling in the North Atlantic (Priede et al. 1991).

The fitted curve of fish numbers with time is different from that observed in the previous study at CNP (Fig. 3). Values for the constants $\alpha_{0}$ and $x$ are similar, suggesting no change in either fish population density or rate of decay of the bait between the 2 studies. However, mean fish staying time, $\beta$, is much shorter (122 min) in this early spring data compared with the previous combined data for summer and autumn (400 min).

$\beta$ is probably related to availability of alternative food sources (Priede et al. 1990) in accordance with the marginal value theorem of food patch utilisation (Charnov 1976). In a food-sparse environment animals stay longer at known food patches. A lower $\beta$ value during early spring suggests a general enrichment in food supply compared with summer and autumn. The question arises then as to whether there is any evidence for temporal changes in food supply at CNP. Such variation could be a seasonal effect or the result of an episodic enrichment which may have occurred since the previous studies.

Seasonality in the rate of phytodetritus falling to the deep sea from surface layers has been reported in the Atlantic Ocean (Deuser \& Ross 1980, Billett et al. 1983, Lampitt 1985, Rice et al. 1986). These temporal variations in phytodetrital accumulation correlate with an elevation in sediment community metabolism (Graf 1989) and blooms of certain species of Foraminifera (Gooday 1988). Large seasonal fluxes in phytoplankton production are not expected in surface waters in the central North Pacific; nevertheless, there are temporal variations in sediment community metabolism (Smith \& Baldwin 1984b) and particulate organic matter flux to the benthic boundary layer (Smith 1987). The diet of Coryphaenoides yaquinae includes fish and a broad range of benthic invertebrates (Stein 1985). Potential food organisms may aggregate near sedimented organic material and therefore become more readily available to grenadiers. Synchronisation of juvenile production by some invertebrate species (Tyler et al. 1982) with peaks in particulate organic matter might also generate a temporal increase in food availability to grenadiers.

Seasonal migrations result in high numbers of pelagic teleosts (e.g. tuna Thunnus alalunga) in the area of CNP during winter (McGary et al. 1961, Laurs \& Lynn 1977). The appearance of these fish constitutes a possible seasonal elevation in the supply of large food falls (Smith \& Baldwin 1984b). An increase in the availability of such carcasses would correlate well with the reduction in staying time $(\beta)$ observed during early spring at CNP.

This study corroborates the indications of earlier tracking work (Priede et al. 1990) that deep-sea grenadiers move actively over the seafloor rather than 


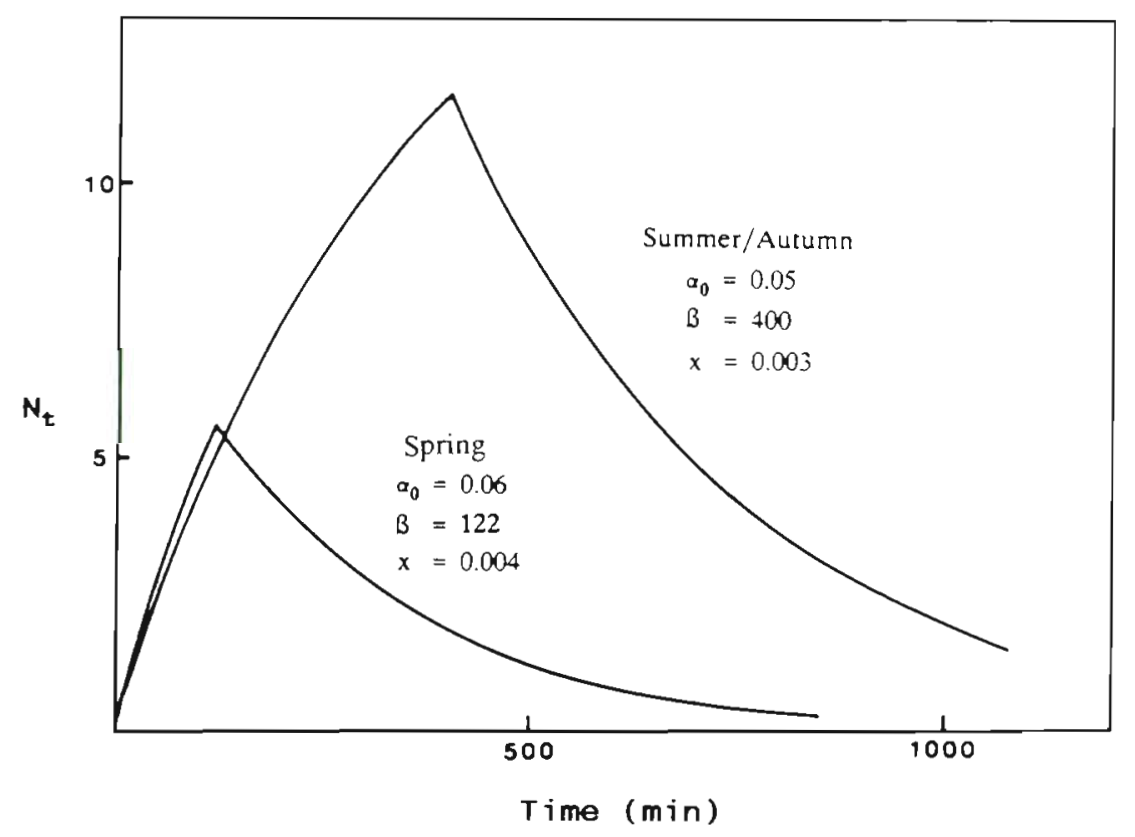

Fig. 3. Coryphaenoides (Nematonurus) yaquinae. Temporal variation in numbers of fish $\left(\mathrm{N}_{\mathrm{t}}\right)$ in camera view. Curves show best-fit line (see text) to data for mean number of fish at time after vehicle landing during spring and summer/autumn (from Priede et al. 1990). Parameters of the curves are: $\alpha_{0}$, initial arrival rate (fish $\mathrm{min}^{-1}$ ); $\beta$, staying time (min); $x$ bait decay constant

maintaining a fixed localised home range. The similar results from widely differing areas, Stris $F$ and CNP, show that active foraging is widespread in the abyssal Pacific grenadiers. It is possible, however, that large carcasses may become a focal point of attraction for a subgroup of the population. This study demonstrates that foraging behaviour of Coryphaenoides (Nematonurus) yaquinae at CNP changes on a temporal basis, probably reflecting variations in food availability. The observed changes constitute a single deviation from previous observations, and further sampling throughout the year is required to test whether the change in foraging behaviour is a routine seasonal phenomenon.

Acknowledgements. We gratefully acknowledge the excellent assistance given by R. Baldwin, J. Edelman, T. Diack and B. Wilson during this work. The project was supported financially by grants to I.G.P. from the NERC (GR3/6611) and the Wolfson Foundation, and to K.L.S. from the NSF (OCE 87-22991).

\section{LITERATURE CITED}

Armstrong, J. D., Baldwin, R. J. (1990). A method for testing retention of transmitters swallowed by deep-sea fish. J. Fish Biol. 36: 273-274

Baldwin, R. J., Smith, K. L. Jr (1987). Temporal variability in the catch rate, length, color and sex of the necrophagous amphipod, Eurythenes gryllus, from the central and eastern North Pacific. Deep Sea Res. 34: 425-439

Billet, D. S. M., Lampitt, R. S., Rıce, A. L. Mantoura, R. F. C. (1983). Seasonal sedimentation of phytoplankton to the deep-sea benthos. Nature, Lond 302: 520-522

Charnov, E. L. (1976). Optimal foraging: the marginal value theorem. Theor Populat. Biol. 9: 129-136

Deuser, W. G., Ross, E. H. (1980). Seasonal change in the flux of organic carbon to the deep Sargasso Sea. Nature, Lond. 283: $364-365$

Gooday, A. J. (1988). A response by benthic Foraminifera to the deposition of phytodetritus in the deep-sea. Nature, Lond. 332: 70-73

Graf, G. (1989). Benthic pelagic coupling in a deep-sea benthic community. Nature, Lond. 341. 437-439

Ingram, C. L., Hessler, R. R. (1983). Distribution and behavior of scavenging amphipods from the central North Pacific. Deep Sea Res. 30: 683-706

Lampitt, R. S. (1985). Evidence for the seasonal deposition of detritus to the deep-sea floor and its subsequent resuspension. Deep Sea Res. 32: 885-897

Laurs, R. M., Lynn, R. J. (1977). Seasonal migration of North Pacific Albacore, Thunnus alalunga, into North American coastal waters: distribution, relative abundance, and association with transition zone waters. Fish. Bull. U.S. 75: 795-822

McGary, J. W. Graham, J. J., Otsu, T (1961). Oceanography and North Pacific Albacore. Rep. Calif. coop. ocean. Fish Invest. (CalCOFI) 8: 45-53

Priede, I. G., Smith, K. L. Ir (1986). Behaviour of the abyssal grenadier, Coryphaenoides yaquinae, monitored using ingestible acoustic transmitters in the Pacific Ocean. $J$. Fish Biol. 29 (Suppl. A): 199-206

Priede, I. G., Smith, K. L. Jr, Armstrong, J. D. (1990). Foraging behavior of abyssal grenadier fish: inferences from acoustic tagging and tracking in the North Pacific Ocean. Deep Sea Res. 37. 81-101

Priede, I. G., Bagley, P. M., Armstrong, J. D., Smith, K. L. Jr, Merrett, N. R. (1991). Direct measurements of active dispersal of food-falis by deep-sea demersal fishes. Nature, Lond. 351. 647-649

Rice, A. L., Billett, D. S. M., Fry, J., John, A. W G., Lampitt, R. S., Mantoura, R. F. C., Morris, R. F. (1986). Seasonal deposition of phytodetntus to the deep-sea. Proc. R. Soc. Edinb. 88B: 265-279

Smith, K. L. Jr (1987). Food energy supply and demand: a discrepancy between particulate organic carbon flux and sediment community oxygen. consumption in the deepsea. Limnol Oceanogr. 32: 201-220 
Smith, K. L. Jr, Baldwin, R. J. (1984a). Vertical distribution of the necrophagous amphipod. Eurythenes gryllus, in the North Pacific: spatial and temporal variation. Deep Sea Res. 31: 1179-1196

Smith, K. L. Jr, Baldwin, R. J. (1984b). Seasonal fluctuations in deep-sea sediment community oxygen consumption: central and eastern North Pacific. Nature, Lond. 307: 624-625

Stein, D. L. (1985). Towing large nets by single warp at abyssal depths: methods and biological results. Deep Sea Res. 32: 183-200

Tyler, P. A., Grant, A., Pain, S. L., Gage, J. D. (1982). Is

This note was submitted to the editor annual reproduction in deep-sea echinoderms a response to variability in their environment? Nature, Lond. 300: $747-750$

Wilson, R. R. Jr. Smith, K. L. Jr (1984). Effect of near bottom current on detection of bait by the abyssal grenadier fishes Coryphaenoides spp., recorded in situ with a video camera on a free vehicle. Mar Biol. 84: 83-91

Wilson, R. R. Jr, Waples, R. S. (1983). Distribution morphology and biochemical genetics of Coryphaenoides armatus and C. yaquinae (Pisces: Macrouridae) in the central and eastern North Pacific. Deep Sea Res. 30: 1127-1145

Manuscript first received: April 15, 1991

Revised version accepted: July 30, 1991 